\title{
Viver para ser velho? Cuidado de si, envelhecimento e juvenilização
}

Resumo: O artigo parte do princípio de que na cibercultura a tecnociência, os meios de comunicação e o mercado oferecem diversificados cardápios de técnicas, produtos e conselhos para aumentar progressivamente a quantidade e a qualidade de vida. Nesse contexto, tradicionais fronteiras entre juventude e envelhecimento são progressivamente questionadas, desafiadas, borradas e vencidas. A juventude eterna passa a ser um projeto político, científico e amplamente sedutor. Este artigo se inscreve no debate em torno dessas questões, colocando em dúvida alguns discursos que ressaltam uma certa valorização da velhice. O argumento principal que desenvolvemos é o de que discursos e representações amplamente difundidos sobre as diversas possibilidades de manter a aparência juvenil dos corpos em processo de envelhecimento são indicativos de que este só é celebrado na medida em que estes corpos se submetem a um conjunto de intervenções técnicas que visam o seu rejuvenescimento. Assim, o que defendemos neste ensaio é que a valorização do envelhecimento vem articulada a um processo de intensa juvenilização da velhice. É por meio de sua juvenilização que a velhice tem sido positivamente enfocada e se coloca no centro das performances físicas e mentais prescritas para, e demandadas dessa população.

Palavras-chave: Corpo. Envelhecimento. Velhice.

Antes de mim vieram os vethos

Os jovens vieram depois de mim

E estamos todos aqui

No meio do caminho dessa vida

Vinda antes de nós

E estamos todos a sós

No meio do caminho dessa vida

E estamos todos no meio

Quem chegou e quem faz tempo que veio

Ninguém no início ou no fim

Antes de mim

Vieram os velhos

Os jovens vieram depois de mim

E estamos todos ai

Adriana Calcanhoto. Velhos e jovens.

\section{Introdução}

A esperança de vida da população mundial foi duplicada nos últimos cem anos. Nossos corpos têm se tornado mais resistentes e duram mais. Governos dos mais diversos países e povos de diferentes culturas celebram o prolongamento da vida. E tais celebrações positivam mais do que o aumento quantitativo da vida.
Edvaldo Souza Couto

Professor Associado na Faculdade de Educação da

Universidade Federal da Bahia UFBA

edvaldosouzacouto@gmail.com

Dagmar Estermann Meyer

Professora da Universidade Federal do Rio Grande do Sul- UFRGS

dagmaremeyer@gmail.com 
A tecnociência, o mercado e os meios de comunicação produzem e fazem circular diversificados cardápios de técnicas, produtos e orientações que visam, sobretudo, o aumento progressivo da qualidade de vida. Nesse contexto, tradicionais fronteiras entre juventude e envelhecimento têm sido cada vez mais questionadas, desafiadas, deslocadas, borradas. Promessas anunciadas, e amplamente desejadas, apontam para possibilidades de reprogramação de corpos humanos na direção de torná-los imunes a doenças, de dar-lhes condições de diminuir as penúrias da velhice e adiar a fatalidade da morte. Nesse contexto, o prolongamento da juventude de corpos e mentes passa a ser um projeto político, científico e cultural amplamente difundido e fomentado.

Este artigo se inscreve no debate em torno dessas questões, colocando em dúvida uma discursividade que ressalta uma certa valorização da velhice contemporânea. O argumento principal que desenvolvemos é o de que discursos e representações amplamente difundidos sobre as diversas possibilidades de manter a juventude de corpos e mentes em processo de envelhecimento são indicativos de que este é celebrado, sobretudo, quando estes se submetem a um conjunto de intervenções técnicas que visam o seu rejuvenescimento. Assim, o que defendemos neste ensaio é que a valorização do envelhecimento vem articulada a um processo de intensa juvenilização da velhice. É por meio de sua juvenilização que a velhice tem sido positivamente enfocada e se coloca no centro das performances físicas e mentais prescritas para, e demandadas dessa, população.

\section{Adeus ao evelhecimento?}

A celebração da juventude manifesta-se de muitas e variadas maneiras nas sociedades ocidentais contemporâneas. Nelas, ideais e tecnologias para manter-se jovem proliferam e são incessantemente divulgadas e legitimadas. Manter-se jovem torna-se um imperativo. É preciso ser jovem e, quando se deixa de sê-lo, é preciso investir no próprio rejuvenescimento, abolindo qualquer sinal na pele que traduza marcas do tempo, revitalizando o corpo e a mente, adotando uma vida ativa e performática e mantendo a saúde e a boa forma a qualquer custo. Tudo isso articulado ao imperativo do prazer que deve ser perseguido e vivenciado indefinidamente. 
Quanto mais o ser jovem se converte em meta da existência, mais a velhice é considerada a partir de percepções negativas, sombrias e, no mais das vezes, aquilo que não mais se admite ou tolera. Ser velho é tudo aquilo que deve ser evitado e afastado de nossos corpos mutantes. (COUTO; GOELLNER, 2009) Para os defensores e construtores de corpos sempre jovens, a velhice é uma ameaça constante e o envelhecimento deve ser vencido, diariamente, por meio das múltiplas técnicas disponíveis para turbinar e revitalizar a corporalidade.

Para muitos, o medo de ser reconhecido e nomeado como velho se deve a determinadas representações de velhice, elaboradas ao longo dos tempos, nas quais esta é significada como incapacidade, decrepitude física e mental e improdutividade, e associada com ausência de prazer sexual, presença de doenças e sofrimentos, solidão, discriminação, dependência, perda da dignidade e proximidade com a morte. Numa sociedade que tanto valoriza a produtividade, a concorrência, a eficiência e as performances jovens, o envelhecimento é considerado como perda da força de produção. E quando alguém ou um grupo passa a ser representado como improdutivo, é também inserido em um processo de marginalização e de desvalorização.

A noção de produtividade está fortemente conectada às noções de juventude e adultez e essa articulação produz, concomitantemente, a significação da velhice como peso familiar e social, uma vez que sujeitos velhos não seriam mais produtores nem reprodutores. (BOSI, 1995, p. 77) Num mundo em que também a velocidade se torna valor preponderante, em que as emoções aventureiras não cessam de ser incentivadas e celebradas, a lentidão das pessoas velhas chega a ser considerada por muitos uma agressão cultural. (NERI, 2007) Nesse sentido, envelhecer pode ser significado como uma transgressão desses valores centrais das sociedades ocidentais contemporâneas nos quais se conectam juventude com capacidade de trabalho, vitalidade e sedução. E, nesse contexto, nosso medo de envelhecer é, também, o medo de ser desqualificado pela idade.

Entretanto, ao mesmo tempo em que as sociedades ocidentais negam e renegam a velhice, elas também não cessam de celebrar o aumento da expectativa de vida de suas populações. Não se deseja envelhecer, mas, paradoxalmente, deseja-se viver mais: acrescentar anos à vida postergando, ao máximo, o envelhecimento. 
Nesse âmbito tem-se investido, então, em um processo de ressignificação em que a velhice vem sendo associada, crescentemente, com vida ativa, saúde, erotismo e felicidade. Desencadeia-se um processo de gerenciamento da velhice no qual pessoas mais velhas passam a ser concebidas como um segmento de mercado ao qual se direciona o consumo de determinados produtos e técnicas múltiplas para o cuidado de si, sob a lógica do turbinamento, do rendimento corporal e do prazer. Agora, juventude, saúde e bem-estar são também commodities e podem ser compradas pelo sujeito que, tendo deixado de ser jovem, quer viver mais e melhor.

Agora, dizem, as pessoas idosas constituem um segmento social e cultural, são sujeitos de direitos específicos e são constantemente estimuladas a adotar renovadas formas de viver. E essa discursividade incide sobre representações de velhice que a definem como etapa natural de fragilização e declínio de vida para promover sua positivação renomeando-a como "terceira idade" ou "melhor idade". (ALVARENGA; MEYER, 2011) Muitos desses enunciados valorativos do envelhecimento, entretanto, não são novos, e podem ser observados nas análises feitas por Foucault (2005; 2010b; 2010c) acerca do cuidado de si, na Grécia Clássica, quando articula esta cultura do cuidado de si a um processo de preparação para a velhice.

Nesses estudos, Foucault descreve e problematiza práticas de cuidado de si, nas quais as melhores maneiras de conduzir a vida são articuladas a uma certa concepção de liberdade e é no contexto dessa articulação que se produz a ideia - nova naquele tempo e lugar - da velhice como um momento e condição privilegiada, que demanda preparação; esta ideia sustenta que a velhice, se devidamente preparada, pode ser vivida como um momento positivo, de realização, a culminação de tudo aquilo que o indivíduo conseguiu realizar.

Essa noção de cuidado de si como preparação para a velhice supõe que o sujeito deve cuidar de si, ocupar-se de si ao longo de toda a vida, em um processo complexo que se inicia na juventude e que encontra seu apogeu na maturidade. Uma das consequências dessa forma de conceber o cuidado de si é o valor que a velhice passa a ter. Como escreve Foucault (2010c, p. 98):

\footnotetext{
Ora, a partir do momento em que o cuidado de si precisa ser praticado durante a vida, principalmente na idade adulta, e em que se assume todas as suas dimensões e efeitos durante o período da plena idade adulta, compreende-se bem que o
} 
coroamento, a mais alta forma do cuidado de si, o momento da sua recompensa, estará precisamente na velhice.

Se a juventude é marcada pela instabilidade, a velhice, sob essa ótica, é o lugar que oferece segurança. Não por acaso, Foucault (2010b) afirma que se deve "viver para ser velho". Nessa perspectiva, não se trata de uma velhice cronológica, mas também de um estado de espírito, que é preciso construir ao longo da vida.

No fundo, é preciso que, a cada momento, mesmo sendo jovens, mesmo na idade adulta, mesmo se estivermos ainda em plena atividade, tenhamos, para com tudo o que fazemos e somos, a atitude, o comportamento, o desapego e a completude de alguém que já tivesse chegado à velhice e completado a sua vida. Devemos viver nada mais esperando da vida e, assim como o idoso é aquele que nada mais espera da vida, devemos, mesmo quando jovens, nada esperar. Devemos consumar a vida antes da morte. (FOUCAULT, 2010c, p. 100)

A velhice incluiria então, nessa perspectiva, o privilégio de dar-se tempo, de cultivar os bons hábitos, de praticar o cuidado de si como uma arte de viver construída como meta ao longo da vida. O cuidado de si se constitui, então, como prática de preparação e, ao mesmo tempo, de realização da velhice, uma forma de encaminhar-se para a própria plenitude. Uma plenitude que não se alcança apenas nos derradeiros momentos, mas ao longo de toda uma vida marcada pelos cuidados de si. O viver para ser velho consistiria, desde essa perspectiva, libertar-se das muitas amarras das ocupações ordinárias que aprisionam e escravizam, libertando-se especialmente do esquecimento da própria velhice.

Baseado/a nesse estudo de Foucault, pensamos que é possível dizer que, para sustentar e difundir atualmente essa perspectiva da "terceira idade" como "boa velhice", fragmentos desses discursos ressurgem em um contexto bem diferente daquele que os originaram e aí, onde parece triunfar a valorização da velhice em si, deparamo-nos com a valorização de um processo que supõe sua juvenilização. É importante atentar para o fato de que certas contradições paradoxais são aqui instaladas, pois partes desses discursos de uma velhice otimizada e positivamente valorada em si mesma pelo cuidado de si, foram deslocados e incorporados aos argumentos contemporâneos que enfatizam o fato de que o 
envelhecimento ativo é aquele que se manifesta por meio de uma luta incessante para não se envelhecer.

Desse modo, entre nós, os valores perseguidos e cultuados nessa época em que as pessoas vivem e buscam mais e melhor qualidade de vida não se vinculam, necessariamente, à preparação para bem viver a velhice, como estudou Foucault. Agora, as pessoas que fazem parte da chamada "terceira idade", sob essa recente lógica da produção, da atividade e da excitação biotecnológica dos corpos, são valoradas na medida em que forem capazes de voltar a ocupar postos de trabalho, ou de produzir e espetacularizar o seu dia a dia de muitas e criativas maneiras. Assim, talvez seja preciso colocar em questão essa propagada valorização da "terceira idade" indagando-nos acerca dos tipos de envelhecimento integrantes dessa representação que posiciona pessoas velhas como sendo dotadas de poderes especiais na dinâmica social e cultural da vida ativa atual. Não seriam esses discursos e práticas do "envelhecimento feliz" uma maneira de promoção sutil do desprestigiamento da velhice, na medida em que a juvenilização parece promover a desqualificação do sujeito que aparenta a idade que tem e se assume como velho?

Atualmente, parece que o envelhecimento só é aceito na medida em que ele mesmo é negado e renegado. O envelhecimento que é festejado parece ser aquele que não cessa de ser elaborado a partir das marcas e dos ideais do rejuvenescimento. Já não se trata apenas do desejo de parar o tempo, mas de fazê-lo movimentar-se em direção contrária, para trás. A primeira condição para esse revés é a consciência de que o envelhecimento é sorrateiro, se instala tão lenta e faceiramente no corpo que a maioria nem percebe. Então o sujeito audaz deve colocar-se imediatamente e desde sempre em estado de alerta, lançar-se vorazmente num mercado de produtos e técnicas capazes de reverter o peso do tempo sobre os corpos.

O que nas últimas décadas se propaga é que é possível viver e viver muito bem na "terceira idade". Mas, viver a "terceira idade" é, sobretudo, estar lá como se lá não se estivesse, pois a visibilidade corporal deve estar sempre dada a partir de uma idade anterior, aquela assinalada pelos ideais e formas da juventude que, sob hipótese alguma, deve ser negligenciada ou perdida. E isto significa, sobretudo, que é preciso vigilância contínua para afastar, controlar e administrar os pequenos sinais da velhice que sorrateiramente 
insistem em se instalar no corpo que, na lógica da exuberância, deveria ser sempre jovem. A velhice muitas vezes é representada como perigosa porque é imperceptível, vai-se instalando por meio de uma lentidão corrosiva que marca o rosto, penetra os tecidos, caminha no silêncio das células, enfraquece os músculos, diminui a energia. A velhice é particularmente difícil de assumir porque nós a consideramos sempre uma espécie de estrangeira. (BEAUVOIR, 2003) Para a grande maioria, a velhice é, de todas as realidades humanas, a que por longo tempo permanece a mais abstrata, pois nunca se seria velho de fato.

Então, esse estar em alerta para não ser surpreendido pela velhice pode até parecer inserido nos ideais dos cuidados de si que preparam o sujeito para o ápice da vida, como estudou Foucault (2010b ; 2010c). Mas é preciso não se deixar enganar, pois, ao mesmo tempo, o que atualmente é chamado de cuidado de si parece seguir, simultaneamente, outras diretrizes que não as da preparação do sujeito para o envelhecimento ativo e qualificador. Agora, a sutileza, é que o chamado cuidado de si passa a ser entendido e tecnicamente aplicado de modo diferente daquele amplamente discutido por Foucault, na medida em que deve colocar o sujeito exatamente na contramão da velhice. Essa compreensão do cuidado de si, traduzido em muitos aspectos do chamado culto ao corpo contemporâneo, tem o objetivo de empurrar alegremente o vivente em direção contrária, para o rejuvenescimento. Cuidar de si, agora, pode significar não se permitir mais envelhecer. Nesse sentido, o cuidado de si, na nossa época, é a construção tecnocultural do juvenilização, pois só no corpo sempre jovem, performático e ativo se pode obter a sensação de completude da existência.

Sem exagero, pode-se dizer que, nos dias atuais, ao invés de envelhecimento, vive-se um processo técnico de rejuvenescimento constante. É preciso viver desperto, atento, ser capaz de vigiar cada detalhe do corpo, recorrer às técnicas cirúrgicas, terapias, medicamentos, exercícios e cosméticos capazes de prolongar cada vez o estado de juventude. Todos esses procedimentos, que fazem parte de um repertório técnico e cultural cada vez mais familiar, são exemplos de meios pelos quais é possível cuidar de si - do corpo, da saúde, do bem-estar performático e dos prazeres - para ser sempre jovem. Cuidar se si, hoje, é sinônimo de não aparentar ter a idade que se tem. 
$\mathrm{Na}$ nossa sociedade existe pouco lugar para a velhice que continua. Por mais paradoxal que pareça, agora tem mais lugar para a velhice que regride, a que rejuvenesce e se sustenta no dinamismo festeiro e emocional dos modos de vida sempre jovens. De certo modo, parece que foi decretada a proibição de envelhecer e morrer de velhice. Agora só se morre, quando se morre, de juventude prolongada, pois o imaginário da juventude triunfa e se dissemina, redefine domínios do corpo e da vida. Agora, no auge da juventude ou na chamada "terceira idade", vivemos sob o signo do juvenilização. E a hegemonia dos discursos e das representações da juvenilização podem estar indicando a busca de um adeus, quiça definitivo, do envelhecimento.

A relação do sujeito contemporâneo consigo mesmo parece se organizar, sobretudo, sob a lógica da publicidade e do consumo. Agora, sob muitos aspectos, a cultura de si aparece sob a forma do prolongamento da vida e a aparente valorização das pessoas idosas segue as metamorfoses da Pover Age, que em certa medida banaliza o cuidado de si e a preparação para a velhice, no rol sem restrição do consumo de produtos e serviços capazes de garantir o rejuvenescimento dos corpos.

Talvez a principal razão da crescente valorização de idosos esteja no fato de que eles se tornaram, na sociedade de consumo, uma classe que se dedica plenamente ao presente, constrói o corpo rejuvenescido, conserva a boa forma, a saúde, a sexualidade agitada. Atualmente, é pelo consumo que cada um pode aproveitar intensamente a vida. De acordo com Lipovetsky (2007, p. 121), vivemos agora a era do "vovô-boom":

Foi-se a época em que os aposentados estavam esgotados, com poucos anos por viver, em que os avós se contentavam em cuidar dos netos. Criados na sociedade de consumo, os seniores viajam, partem para o outro extremo do mundo, visitam cidades e museus, fazem cursos de informática, praticam esportes, querem parecer "mais jovens". A bulimia consumista já não é interrompida pela idade: a geração do vovô-boom mostra-se ávida de evasões distrativas, de maior bem-estar, de qualidade de vida associada ao consumo de produtos dietéticos, aos prazeres do turismo, aos cuidados cosméticos.

Desse modo, através do consumo, pois nenhuma idade escapa às redes do marketing, muitos alardeiam um suposto fim da cultura antivelho, em que o ostracismo e a negligência para com os idosos 
estariam, enfim, superados, em nome de um regime tolerante e pluralista da vida. Esse discurso, cada vez mais hegemônico, se revela bastante sedutor. Ao mesmo tempo em que libera o sujeito, simultaneamente, desenvolve outras estratégias de sujeição. É preciso desconfiar dessa propagandeada liberação das pessoas idosas por intermédio do consumo, pois muitos e diferentes campos do pensamento, dos saberes, das práticas políticas e midiáticas se apropriam dessa liberação e, não raro, elaboram outras formas de aprisionamento.

Um desses possíveis aprisionamentos é a própria crença de que o "viver para ser velho" naturaliza, pelo consumo, a velhice em nossa sociedade ocidental. Se os seniores estão mais visíveis, e são bajulados pela publicidade que aquece o consumo, é porque eles mesmo desejam cuidar de si não para preparar-se para o envelhecimento, mas para permanecer jovens, ativos e sedutores. É a juvenilização que triunfa nos comportamentos, consumo das práticas de si e aspirações de cada um. Nesse sentido, o "viver para ser velho" em qualquer fase da vida se metamorfoseia num "viver para parecer jovem" em toda e qualquer etapa da existência. E isso, mais do que valorização, seria o fim da velhice, porque ela já foi pulverizada e disseminada nos muitos modos de consumo, quando as práticas e técnicas do cuidado de si foram contaminadas e sujeitadas pelo juvenilização sem fronteiras. Como afirma Foucault (2005), as redes de poder alocadas nessa construção cultural de corpos eternamente jovens, sob as táticas irresistíveis da boa forma e boa saúde, de uma performance corporal sempre mais intensa e inusitada, produzem novos espaços de enfrentamento. Agora, é sob os ideais festivos do rejuvenescimento, sob esse cuidado virtuoso de si, que o envelhecimento se mascara e se torna tolerável.

\section{Algumas conclusões}

Diante da complexidade das relações culturais que vivemos, tradicionais fases de vida como nascer, crescer, reproduzir, envelhecer e morrer, que correspondiam à infância, juventude, idade adulta e velhice não dão mais conta dos movimentos, arranjos, vivências e desejos de mulheres e homens. É por meio do consumo dessa maturidade ativa que pessoas mais velhas passam a ocupar a cena, lutar por direitos, reivindicar aventuras e gozos antes reservados aos que se encontravam na chamada flor da idade. 
Alguns aspectos dessa discussão merecem ser ressaltados e apontam um conjunto de conclusões ou, se preferirmos, de consequências. Destacamos três delas: em primeiro lugar, os discursos aparentemente valorativos da chamada "terceira idade" não significam necessariamente afirmação da velhice. Como procuramos argumentar, sob vários aspectos significam mais uma forma de negação, pois a "terceira idade", construída na performatividade da vida ativa, só existe ou faz sentido ao renegar a si mesma, quando aparece travestida de uma juventude turbinada pelos muitos produtos disseminados no mercado para impedir e, talvez, como muitos acreditam, eliminar a velhice.

Em segundo lugar, a suposta valorização da velhice ativa decreta o adeus à velhice ao afirmar apenas o corpo rejuvenescido como digno de existir e se exibir. Esse deslocamento é bem paradoxal. Para os corpos rejuvenescidos, o ideal de bem viver, o aprender a ser velho em toda e qualquer idade, só é possível quando se tornam, ao mesmo tempo, sujeitos de outro discurso: o que sugere que o bem viver não é outra coisa senão recusar-se a envelhecer, pois agora a gordura, flacidez, rugas, manchas, estrias, celulite, varizes, entre outros sinais da organicidade perecível e da finitude biológica, fazem parte dos horrores da carne dos desleixados, daqueles que não sabem ou não se dedicam aos cuidados de si. De acordo com esse entendimento, cuidar de si significa, pois, não se deixar envelhecer em época alguma.

Por fim, talvez seja possível dizer que, em um tempo em que se celebra o aumento da expectativa de vida, ao mesmo tempo, envelhecer se torna cada vez mais intolerável. Isto quer dizer que supostas representações valorativas do corpo idoso parecem se impôr pelas lógicas sedutoras e irresistíveis do mercado. Deixar de ser velho, frear o envelhecimento, quer dizer refazer continuamente o seu corpo, entregar-se a toda sorte de produtos e saberes aparentemente capazes de nos fazer escapar do tempo. Sob a lógica do espetáculo, restam esses corpos consumidores que se dedicam a comprar um determinado tipo de corpo: aquele que se considera válido ou bom, isto é, aquele que se constitui a partir de uma aparência jovem, borbulhante e renovável. (COSTA, 2004) A juvenilização se torna uma crença das mais vigorosas da nossa época: a de que os nossos corpos, se quisermos e investirmos neles, não mais envelhecem. 
Essas produções de corpos rejuvenescidos, difundidas em toda parte, são modos de construir e festejar as subjetividades na cibercultura. Esses corpos que não cessam de ser modificados fazem parte das aventuras do humano em tempo de mutações e conexões ilimitadas. Ao mesmo tempo, assinalam as nossas extraordinárias precariedades corporais amplamente compartilhadas, carentes de entendimentos e rearranjos. Antes de mim vieram os velhos. Os jovens vieram depois de mim. E estamos todos aí.

\title{
Living to be old? Self-care, aging and juvenilization
}

\begin{abstract}
This paper is based on the principle that, in cyberculture, techno-science, means of communication and market offer a diversified menu of techniques, products and advice to progressively increase both the length and quality of life. In this context, traditional boundaries between youth and aging have been increasingly questioned, defied, blurred and surpassed. The eternal youth has become a political, scientific project that is widely seductive. This paper participates in the debate about these issues, questioning some discourses that have highlighted a certain valorization of old age. The main argument here developed is that widely spread discourses and representations of the countless possibilities of keeping aging bodies with a young appearance are signs that such aging process is only celebrated if these bodies undergo a set of technical interventions aiming at their rejuvenation. Thus, what is advocated in this essay is that the valorization of the aging process is articulated with a process of intense juvenilization of old age. It is by means of its juvenilization that old age has been positively focused and put at the center of physical and mental performances prescribed for, and demanded by, this population.
\end{abstract}

Key words: Body. Aging. Old age.

\section{Referências}

ALVARENGA, Luiz F.; MEYER, Dagmar E. Práticas contemporâneas de significação e (re)produção de corpos velhos: um olhar a partir dos estudos de gênero e culturais. In: STREY, Marlene Neves et al. (Org.) Gênero e ciclos vitais. Porto Alegre: EDIPUCRS, 2011. (No prelo).

BEAUVOIR, Simone. A velhice. 5. ed. Tradução de Maria Helena Franco Monteiro. Rio de Janeiro: Nova Fronteira, 2003.

BOSI, Ecléa. Memória e sociedade: lembranças de velhos. São Paulo: Companhia das Letras, 1995.

CASTRO, Edgardo. Vocabulário de Foucault. Tradução de Ingrid Muller Xavier. Belo Horizonte: Autêntica, 2009.

COSTA, Jurandir Freire. O vestígio e a aura: corpo e consumismo na moral do espetáculo. Rio de Janeiro: Garamond, 2004.

COUTO, Edvaldo Souza; GOELLNER, Silvana Vilodre (Org.) Corpos 
mutantes: ensaios sobre novas (de)eficiências corporais. 2. ed. Porto Alegre: Editora da UFRGS, 2009.

FOUCAULT, Michel. O governo de si e dos outros. Tradução de Eduardo Brandão. São Paulo: Martins Fontes, 2010a.

. A hermenêutica do sujeito. Tradução de Márcio Alves Fonseca e Salma Tannus Muchail. 3. ed. São Paulo: Martins Fontes, 2010b. Poder-corpo. In: . Microfísica do poder. Tradução de

Roberto Machado. Rio de Janeiro: Graal, 2005. p. 145-152. Resumo do curso. Tradução de Márcio Alves Fonseca e Salma Tannus Muchail. 3. ed. São Paulo: Martins Fontes, 2010c.

GROS, Frédéric. Situação do curso. In: FOUCAULT, Michel. A hermenêutica do sujeito. Tradução de Márcio Alves Fonseca e Salma Tannus Muchail. 3. ed. São Paulo: Martins Fontes, 2010.

LIPOVETSKY, Gilles. A felicidade paradoxal: ensaio sobre a sociedade do hiperconsumo. Tradução de Maria Lúcia Machado. São Paulo: Companhia das Letras, 2007.

NERI, Anita Liberalesco. Atitudes e preconceitos em relação à velhice. In:___ Idosos no Brasil: vivências, desafios e expectativas na terceira idade. São Paulo: Edições SESC-SP; Ed. Fundação Perseu Abramo, 2007. p. 34-46.

Artigo submetido em 05/12/2011, aceito para publicação em 29/03/2012 